\title{
Preventive effect of cyproheptadine hydrochloride in refractory patients with frequent migraine
}

\author{
Hirohisa Okuma*, Kazuyuki lijima, Takashi Yasuda, Kentaro Tokuoka and Yasuhisa Kitagawa
}

\begin{abstract}
Cyproheptadine hydrochloride $(\mathrm{CH})$ is rarely used to treat adult patients with migraine in Japan because it causes sleepiness. In this study, we investigated the preventive effect of $\mathrm{CH}$ in 12 patients who had failed to respond to conventional preventive treatments among 103 migraine patients treated at our hospital. These 12 subjects had all received unsuccessful migraine prophylaxis with lomerizine, valproic acid and topiramate, or had discontinued these treatments due to adverse reactions. Initially, the subjects were given $4 \mathrm{mg} \mathrm{CH}$ before sleeping. In those who experienced no clinically significant sleepiness following the treatment, the drug was orally administered at $4 \mathrm{mg}$ after breakfast as well (8 $\mathrm{mg}$ per day in total). Drug efficacy was evaluated by examining the frequency of migraine at one month and three months after the start of treatment. The frequency of migraine was dramatically reduced in all patients within 7 to 10 days after starting treatment. The average frequency of migraine during the three-month period was 2.6 episodes per month, representing a significant $(p<0.01)$ reduction from the pretreatment frequency of over 10 per month. Our results indicate that $\mathrm{CH}$ may be effective as a migrainepreventive treatment for patients in whom conventional drugs have been ineffective or have caused side effects. But this study is not a double blind randomized trial, and an open study with no control group.
\end{abstract}

\section{Introduction}

In patients who experience frequent migraine attacks, the risk of rebound headache is quite high, and regardless of the efficacy of the rescue medication, there is a need for preventive therapy (Headache Classification Committee of the International Headache Society 2004). Cyproheptadine hydrochloride $(\mathrm{CH})$ is generally used outside Japan as a migraine preventive treatment in pediatric patients (Kara 2010), with excellent results. In Japan, antidepressants, beta-blockers, antiepileptic agents, calcium antagonists, etc., are the main medications used to prevent migraine in adults (Pascual 2012; Tfelt-hansen 2013), and $\mathrm{CH}$ is rarely used in adults, because it causes sleepiness. Consequently, there has been no report on the effectiveness of this drug in adult patients with migraine in Japan. Although $\mathrm{CH}$ as an antihistamine has been largely replaced by nonsedating compounds, it nevertheless has efficacy in preventing migraine attacks (Rao et al. 2000; Lewis et al. 2004), and not just in patients whose migraines are worsened or triggered by underlying allergies. In this study, we investigated the preventive effect of $\mathrm{CH}$ in patients who did not respond to conventional preventive treatments.

\section{Subjects}

The migraine preventive effect of $\mathrm{CH}$ was investigated in 12 of 103 migraine patients treated at our hospital. These 12 subjects ( 1 men and 11 women, average age 35; Table 1) had all received unsuccessful migraine prophylaxis with lomerizine, valproic acid and topiramate, or had discontinued such treatments due to adverse reactions or because of possible fetal side effects during pregnancy. The frequency of their migraine attacks was 10 or more per month. Among these patients, four had migraine with aura, four had migraine without aura, and four had menstrual migraine.

\footnotetext{
* Correspondence: ookuma@hachioji-hosp.tokai.ac.jp

Department of Neurology, Tokai University Hachioji Hospital, 1838

Ishikawa-cho, Hachioji city, Tokyo 192-0032, Japan
} 


\begin{tabular}{|c|c|c|}
\hline \multirow[t]{2}{*}{$n=12$} & \multicolumn{2}{|c|}{ Dose of cyproheptadine hydrocride } \\
\hline & 4 mg/day $(n=8)$ & $8 \mathrm{mg} / \mathrm{day}(\mathrm{n}=4)$ \\
\hline Gender & male: female $1: 7$ & all female \\
\hline Average age & $34 \pm 6$ & $36 \pm 5$ \\
\hline $\begin{array}{l}\text { Frequency of migraine } \\
\text { premedication }\end{array}$ & $8.7 /$ month & $10.6 /$ month \\
\hline $\begin{array}{l}\text { Frequency of migraine one } \\
\text { month after start of treament }\end{array}$ & 1.6/month & $1.2 /$ month \\
\hline $\begin{array}{l}\text { Frequency of migraine three } \\
\text { month after start of treatment }\end{array}$ & 3.1/month & 2.1/month \\
\hline \multirow[t]{2}{*}{ Adverse reactions } & Body weight $28.6 \%$ & Body weight $25.0 \%$ \\
\hline & Sleepiness 14.3\% & Sleepiness 50.0\% \\
\hline
\end{tabular}

\section{Methods}

$\mathrm{CH}$ was orally administered in subjects who had received unsuccessful migraine prophylaxis with lomerizine hydrochloride, valproic acid, and topiramate, or who had encountered side effects with such treatments, or had contraindications. Because $\mathrm{CH}$ may cause sleepiness, $\mathrm{CH} 4 \mathrm{mg}$ was initially given before sleeping. In those who experienced no clinically significant sleepiness following the treatment, the drug was orally administered at $4 \mathrm{mg}$ after breakfast as well. Drug efficacy was evaluated by examining the frequency of migraine at one month and three months after the start of treatment. But this study is not a double blind randomized trial, and an open study with no control group.

\section{Results}

The frequency of migraine was dramatically reduced in all patients within 7 to 10 days after starting treatment. No migraine attacks were observed in 9 of the 12 patients during 1 month after starting the drug. In two other patients, the frequency of monthly migraine attacks was reduced to 1 . The average frequency of migraine attacks during three months was 2.6 times per month. These results indicate that $\mathrm{CH}$ is effective for preventing migraine. The incidences of adverse reactions were $60.7 \%$ for sleepiness and $30.3 \%$ for increased appetite. Sleepiness was alleviated by changing the dose regimen to administration of 1 tablet $(4 \mathrm{mg}$ ) before sleeping. Weight gain caused by increased appetite did not develop into a problem after subjects were advised to pay more attention to their diet. The average frequency of migraine attacks before $\mathrm{CH}$ administration was 8.7 times per month, but this was decreased to 3.1 times per month at 3 months after the start of treatment in the group that received $4 \mathrm{mg}$ per day. The average frequency of migraine attacks before $\mathrm{CH}$ administration was 10.6 times per month in the group that received $8 \mathrm{mg}$ per day, but this was decreased to 2.1 times per month after 3 months. Weight gain was similar in both groups, but sleepiness was more marked in the higher dose group, in which its incidence reached $50 \%$ (Table 1 ). The results of the Willcoxon's signed rank test were as follows. Two groups had a $\rho$-value of 0.01 , and showed a significantly greater contribution than the premedication (Figure 1).

\section{Discussion}

A double-blind study for the migraine prophylaxis by propranol and $\mathrm{CH}$ is reported. Before (Rao et al. 2000), but our study, we performed all prophylaxis to the last, but protective efficacy for the migraine uses $\mathrm{CH}$ only to refractory patients with frequent migraine. Therefore, it was shown to our study that $\mathrm{CH}$ was effective for the refractory patients with frequent migraine.

Involvement of the trigeminal-vascular system (Mathew 2001; Silberstein 2004) is generally considered the most likely cause of migraine. According to this theory, release of serotonin from platelets induces cerebral vasoconstriction and decreases cerebral blood flow, inducing aura, including scintillating scotomata. Subsequent serotonin depletion leads to cerebral vasodilatation and stimulation of the trigeminal nerve, which extends around vessels such as intracranial large vessels and the dura mater, inducing neurogenic inflammation and thus triggering migraine (Ollat 1992; Greek 2006; Hammon \& Hoyer 2008). There are seven types of serotonin receptors. The serotonin 1 and 2 receptors are involved in cerebral vasoconstriction, and the serotonin 1 receptor exists predominantly in cerebral blood vessels. Furthermore, several subtypes of the serotonin 1 receptor have been identified, and among them, the serotonin $1 \mathrm{~B}$ and $1 \mathrm{D}$ receptors are considered to be involved in cerebral vasoconstriction and in causing migraine (Ferrari et al. 2001; Wolff et al. 2003; Filip \& Bader 2009). It has also been shown that binding of serotonin to the serotonin $1 \mathrm{D}$ receptor at trigeminal nerve terminals inhibits release of vasoactive peptides, including calcitonin gene-related peptides.

$\mathrm{CH}$, which we used in this study, is generally used for migraine in pediatric patients, but not adult patients. In addition to its antihistaminic action, $\mathrm{CH}$ exerts antiserotonin and anticholinergic actions, and antagonizes histamine and serotonin receptors. It does not inhibit or chemically inactivate release of histamine and serotonin, but competitively and reversibly antagonizes histamine and serotonin at receptor sites. Therefore, we conclude that $\mathrm{CH}$ showed superior prophylactic efficacy to commonly used drugs in our patients owing to its inhibition of the release of vasoactive peptides, including calcitonin gene-related peptides, with simultaneous inhibition of both serotonin $1 \mathrm{~B}$ and $1 \mathrm{D}$ receptors and prevention of neurogenic inflammation caused by stimulation of the trigeminal nerve in patients with refractory migraine 


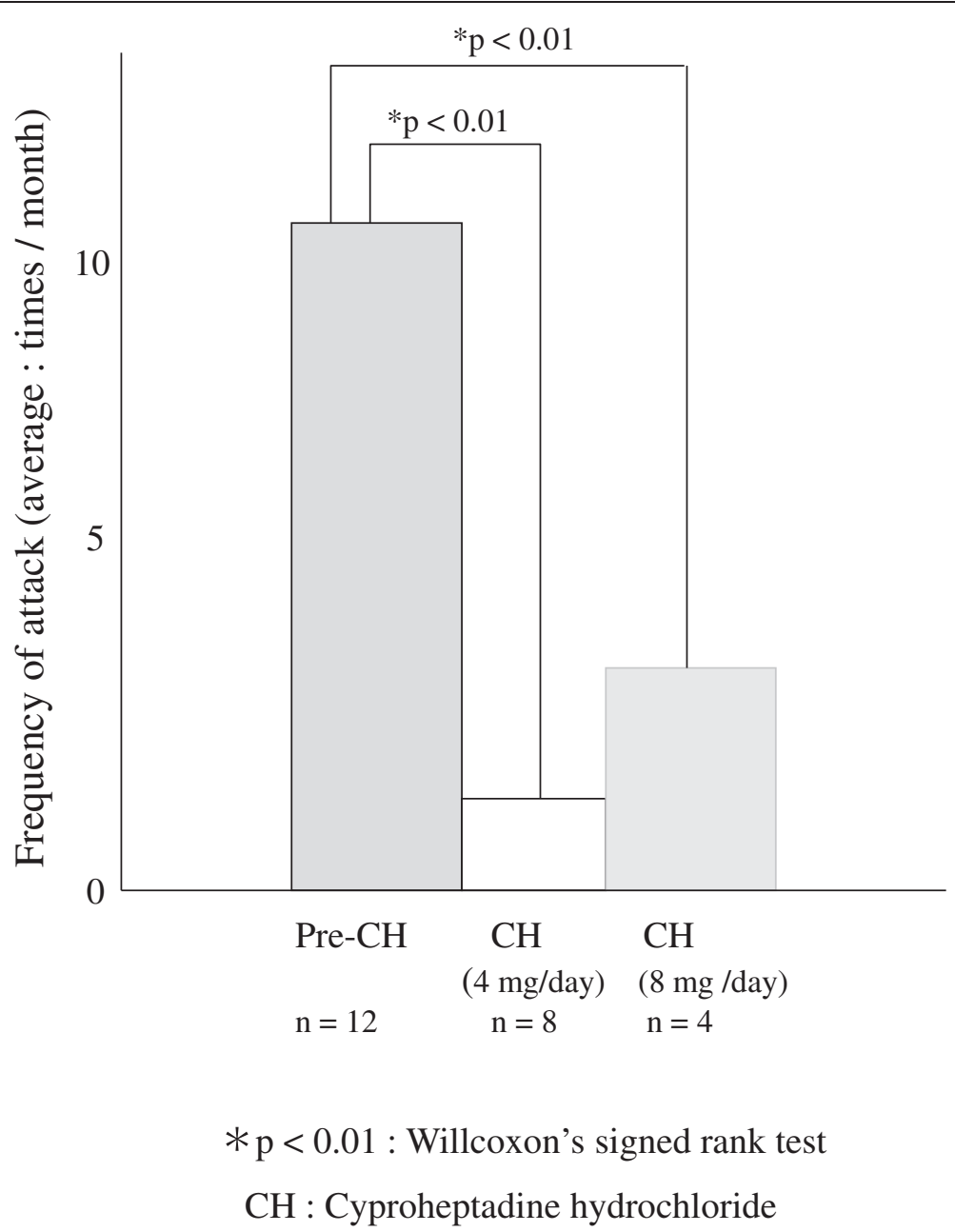

Figure 1 The results of the Willcoxon's signed rank test of the use of cyproheptadine hydrochroride.

(Villalon \& Olsen 2009). Its greater efficacy in patients with allergic rhinitis and refractory migraine is considered to be attributable its antihistaminic action.

Based on the present results, we suggest that even adult patients who do not respond to multiple drugs currently used for migraine prophylaxis should be given preventive therapy with $\mathrm{CH}$. However, since the antiserotonin action of $\mathrm{CH}$ is stronger than that of lysergic acid diethylamide (LSD), great care is needed to prevent the onset of visual hallucinations and confusion, especially at higher doses. Also, weight gain should be anticipated due to stimulation of the feeding center by the anticholinergic action of this drug. Long-term treatment with $\mathrm{CH}$ should be avoided.

\section{Conclusions}

Currently, antidepressants, beta-blockers, antiepileptic agents, and calcium antagonists are used in Japan to prevent frequent, intractable migraine in adults. The results of this study demonstrate that $\mathrm{CH}$ is effective as a migraine-preventive treatment for adult Japanese patients in whom such conventional drugs are ineffective or induce undesirable side effects.

\section{Competing interests}

The authors declare that they have no competing interests.

\section{Authors' contribution}

$\mathrm{HO}$ participated in designing the experimental setup, collected and analyzed the data and drafted the manuscript. Kl participated in designing the experimental setup, participated in analyzing the data and drafted the manuscript. TY participated in designing the experimental setup, participated in analyzing the data and drafted the manuscript. KT participated in designing the experimental setup, participated in analyzing the data and drafted the manuscript. YK participated in designing the experimental setup, participated in analyzing the data and drafted the manuscript. All authors read and approved the final manuscript.

Received: 26 April 2013 Accepted: 15 October 2013 Published: 29 October 2013

\section{References}

Ferrari MD, Roon Kl, Lipton RB et al (2001) Oral triptans-serotonin 5-HT(1B/1D) agonists-in acute migraine treatment: a meta-analysys of 53 trials. Lancet 358:1668-1675 
Filip M, Bader M (2009) Overview on 5-HT receptors and their role in physiology and pathology of the central nervous system. Pharmacol Rep 61:761-777

Greek AR (2006) Neuropharmacology of 5-hydroxytryptamine. Br J Pharmacol 147(Supple 1):145-152

Hammon J, Hoyer D (2008) Molecular biology of 5-HT receptors. Behav Brain Res 195:198-213

Kara SL (2010) Pediatric headache. Pediatr Neurol 17:224-229

Lewis D, Ashwal S, Hershey A et al (2004) Practice parameter: pharmacological treatment of migraine headache in children and adolescents: report of the Americcan academy of neurology quality standards subcommittee and the practice committee of the child neurology society. Neurology 63:2215-2224

Mathew NT (2001) Pathophysiology, epidemiology, and impact of migraine. Clin Comerstone 4:1-17

Olesen J, Bousser MG, Diener HC et al (2004) Headache Classification Committee of the International Headache Society The International Classification of Headache Disorders, 2nd edn. Cephalalgia 24(1):1-160

Ollat H (1992) Serotonin agonists and antagonists in migraine. Pathol Biol 40:389-396

Pascual J (2012) Chronic migraine: treatment. Rev Neurol 54(Suppl 2):31-38

Rao BS, Das DG, Taraknath VR, Sarma Y (2000) A double blind controlled study of propranolol and cyproheptadine in migraine prophylaxis. Neurol India 48:223-226

Silberstein SD (2004) Migraine pathophysiology and its clinical implications. Cephalalgia 24:1045-1048

Tfelt-hansen PC (2013) Evidence-based guideline update: Pharmacologic treatment for episodic migraine prevention in adults: Report of the quality standards subcommittee of the American Academy of Neurology and American Headache Society. Neurology 80:869-870

Villalon CM, Olsen J (2009) The role of CGRP in the pathophysiology of migraine and efficacy of CGRP receptor antagonists as acute antimigraine drugs. Parmacol Ther 124:309-323

Wolff M, Savova M, Malleret G et al (2003) Serotonin 1B knockout mice exhibit a task-dependent selective learning facilitation. Neurosci Lett 338:1-4

doi:10.1186/2193-1801-2-573

Cite this article as: Okuma et al:: Preventive effect of cyproheptadine

hydrochloride in refractory patients with frequent migraine. SpringerPlus $20132: 573$

\section{Submit your manuscript to a SpringerOpen ${ }^{\circ}$ journal and benefit from:}

- Convenient online submission

- Rigorous peer review

- Immediate publication on acceptance

- Open access: articles freely available online

- High visibility within the field

- Retaining the copyright to your article

Submit your next manuscript at $\gg$ springeropen.com 